BAPIOAC19-P04

\title{
Development of an acute general paediatrics service specification at a major London teaching hospital
}

Poster Presentation at BAPIO National Conference, London 2019 Peer reviewed by Subarna Chakravorty PhD \& Sunil Daga PhD

\author{
Julia Avery \\ St George's University Hospital, London \\ Cite as: Avery, J. (2020) Development of an \\ acute general paediatrics service specification \\ at a major London teaching hospital . The \\ Physician vol 6; issue 2; epub 01 Jan 2020; DOI: \\ https://doi.org/10.38192/1.6.2.8

$\begin{array}{ll}\begin{array}{ll}\text { Article Information } \\ \text { Submitted }\end{array} & 01 \text { Nov } 2019 \\ \text { Published } & \text { 01 Jul } 2020 \\ \text { Open Access - Creative Commons Licence CC-BY- } & \\ \text { ND-4.0 } & \end{array}$

\section{Background and aims}

\section{Results}

Sixty two key standards were identified from six different Annually 28,000 patients between the ages of $0-18$ years present acutely to St George's Hospital (mainly via the emergency department or following a GP consultation) and are the responsibility of the Acute General Paediatrics care group. They may be cared for in a number of settings and across a number of pathways of care. To ensure the delivery of a safe, patient centred, high quality service, we created a service specification based on the present plethora of national standards. This would also provide a means for ongoing quality analysis.

\section{Methods}

Relevant guidance was identified through a variety of search methods: direct search of national bodies' websites, expert opinion and liaison with Trust managers to identify standards reported to regulators. guidelines. Thematic analysis of these standards identified nine overarching themes and within each, a number of sub-themes. A Red Amber Green (RAG) rating system was used to identify the performance of the service against each theme. An action plan has been created linked to the service governance strategy to ensure the standards can be achieved in the future.

\section{Conclusion}

The new service specification will be used by clinical staff to reflect on practice and outcomes. It enables clinicians to identify standards, rather than accessing them from various sources. It will aid planning, commissioning and provision of acute paediatric services and provide a framework against which to audit provision and demonstrate improvement. It would be possible to translate this for use across the UK. 